\section{Reducing the Emission of Particles from a Diesel Engine by Adding an Oxygenate to the Fuel}

\author{
KENTE. NORD* AND DAN HAUPT \\ Department of Chemical Engineering and Geosciences, \\ Luleå University of Technology, SE-971 87 Luleå, Sweden
}

Particulate and high emissions of $\mathrm{NO}_{x}$ are the main problems that are associated with diesel engines. Therefore, techniques and fuels that promote a reduction in these emissions currently are attracting great interest. In this paper, a mixture of acetal and regular diesel fuel has been tested in a heavy-duty diesel engine. The effect was a marked decrease in particle number and the estimated particle mass. A small reduction of the engine power was also observed; however, the net effect was nevertheless a reduction in the emission of $\mathrm{CO}_{2}$ per European stationary cycle. The emissions of $\mathrm{HC}, \mathrm{CO}, \mathrm{NO}_{x}$, some aldehydes, and hydrocarbons were only slightly affected by the new fuel composition. An exception was the emission of acetaldehyde, which was almost quadrupled, probably reflecting the decomposition and oxidation of acetal to acetaldehyde.

\section{Introduction}

There is an increased interest in using oxygenates as additives in diesel fuel. The reason for this seems to be political; both the European Union (EU) and the United States have declared their interest in promoting the use of bioenergy $(1,2)$. Numerous studies have also shown that oxygen-containing compounds that are added to diesel fuel reduce the particulate matter $(\mathrm{PM})(3-21)$. In contrast, aldehydes seem to be emitted in somewhat higher levels when oxygenates are added (3-5). $\mathrm{NO}_{x}$ emissions, on the other hand, have been reported to decrease when oxygenates are added $(3,6)$. Different organic compounds (for example, alcohols, ethers, and esthers) have been studied as potential additives to diesel, and the influence of the levels of particles as well as other components have been reported $(3,7-13)$. A general finding is that the reduction of particles seems to be linearly dependent on the oxygen content, and, thus, the blend with the highest oxygen content results in the highest reduction of particles (14-16). Most of the investigations also report that the effect of the chemical structure is negligible, compared to the effect of the oxygen content (14-17). Cheng et al., for example, formulated fuels blends with up to $15 \mathrm{wt}$ $\%$ of oxygen and tested them in a Cummins B 5.9 directinjection diesel engine (14). The reduction of particles was almost linearly dependent on the oxygen content, and, thus, the blend with the highest oxygen content resulted in the highest reduction of particles. The effect of oxygenate chemical structure on measured particulate emissions was small. The authors also suggested, from numerical modeling, several mechanisms in which oxygenates reduce the production of soot precursors and, hence, soot and particles.

* Corresponding author phone: +46 (0)920 4916 67; fax: +46 (0)920 4911 99; E-mail: kent.nord@ltu.se.
Four different oxygenates was tested in a four-valve, threecylinder, 1.26-L prototype engine equipped with common rail fuel injection by Hilden et al. (15). The oxygenate compounds were chosen by the investigators, so that the impact from volatility, concentration, and chemical type (aromatic or aliphatic) on particulate emissions could be studied. Generally, volatility had little effect on emitted particle emissions, whereas increased oxygen content resulted in an increased reduction of particulate emissions. The highest reductions of particulate emissions were observed for tripropylene glycol monomethyl ether and diisobutyl adipate, followed by dipropylene glycol monomethyl ether. The aromatic oxygenate dibutyl phthalate was observed to increase emitted particulate emission.

The effect of five different oxygenates that were added to a low-sulfur diesel fuel and a Fischer-Tropsch fuel was studied by Hallgren and Heywood (16). Particles were measured both in terms of PM (i.e., on filter) and particle size and number emissions, using a scanning mobility particle sizer (SMPS). The total number fraction of particles emitted was approximately the same for all fuels, whereas the volume fraction decreased when oxygenated fuel was used. The reductions of particles were related to the oxygen content and the oxygen-containing functional group. Agreement was observed between the relative trends noticed on the integrated SMPS particle volume fraction and filter-based mass measurement. Preliminary physical and chemical characterization of particulate matter from the reference fuel and oxygenated fuels did not reveal any significant morphological or compositional differences.

In this study 1,1-diethoxyethane, which is an acetal, has been added to diesel fuel. This particular oxygenate has been a subject in several investigations, but neither the emission performance nor combustion performance has been determined to have been reported for the actual compound neat or when blended into diesel $(7,18)$. Other acetals have been studied more extensively. Bertola and Boulouchos found that butylal, which is an acetal compound, offers advantages over other oxygenates because of the fact that its physical properties are very similar to those of common diesel fuel (7). Some preliminary studies with this oxygenate on a singlecylinder research engine showed that butylal substantially reduced the exhaust gas opacity but did not affect the $\mathrm{NO}_{x}$ emissions (7). Butylal was also included in a second investigation, in which one investigated the influence of injection parameters and fuel composition on particulate emissions (20). Two different blends, containing $~ 15 \%$ and $50 \%$ butylal, efficiently reduced both the particle size and number concentrations.

The aim of present study has been to investigate 1,1diethoxyethane as an additive to diesel fuel. Particle number, particle size, and the share of volatile particles have been studied, as well as the emissions of some aldehydes and hydrocarbons. The tests have been performed with a heavyduty engine that was mounted on an engine test bed and operating on low-sulfur Swedish diesel fuel. Engine performance and the emissions of $\mathrm{NO}_{x}, \mathrm{CO}$, and $\mathrm{HC}$ are also reported.

\section{Experimental Section}

Engine and Fuels. A Scania 9 L compression-ignition diesel engine with electronically controlled fuel injection has been used without any emission control. This type of engine is frequently used today and will probably be common for a long period. The emission performance can be improved 
TABLE 1. Fuel Specification and Test Result for the EC-1 Fuel and the Mixture with Acetal

\begin{tabular}{|c|c|c|}
\hline fuel property & $\begin{array}{l}\text { EC-1 diesel, } \\
\text { measured }\end{array}$ & $\begin{array}{c}\text { A-diesel EC-1 } \\
\text { + acetal, } \\
\text { measured }\end{array}$ \\
\hline density $\left(\mathrm{kg} / \mathrm{m}^{3}\right)$ & 815 & 810 \\
\hline $\begin{array}{l}\text { cetane number } \\
\text { distillation }\left({ }^{\circ} \mathrm{C}\right)\end{array}$ & 52 & 51 \\
\hline initial bp & 180 & 109 \\
\hline 95\% distilled bp & 285 & 286 \\
\hline flash point $\left({ }^{\circ} \mathrm{C}\right)$ & $>60$ & $32^{a}$ \\
\hline $\begin{array}{l}\text { CFPP, cold filter } \\
\text { plugging point }\left({ }^{\circ} \mathrm{C}\right)\end{array}$ & -35 & less than -35 \\
\hline cloud point $\left({ }^{\circ} \mathrm{C}\right)$ & -24 & -40 \\
\hline viscosity, $40^{\circ} \mathrm{C}\left(\mathrm{mm}^{2} / \mathrm{s}\right)$ & 1.9 & 1.6 \\
\hline corrosivity, copper corrosion & $1 \mathrm{~A}$ & $1 \mathrm{~A}$ \\
\hline lubricity, HFRR ( $\mu \mathrm{m})$ & 350 & 367 \\
\hline thermal value (MJ/kg) & 43.1 & 32 \\
\hline
\end{tabular}

with emission control, i.e., exhaust gas recirculation (EGR) and diesel particulate filters (DPFs) $(22,23)$.

The engine technology is somewhat outdated, compared to the most advanced engines on the market today. Stateof-the art heavy-duty diesel engines use unit injectors or common-rail systems. It can also be noted that the engine has two valves in the cylinder head, whereas modern engines normally have four valves. The design with four valves utilizes a central nozzle, which reduces emissions, because of a more uniform fuel spray.

Several factors are of the greatest concern when new fuels or fuel compositions are introduced into the market. First, the fuel must fulfill valid fuel specifications, to give proper function to the engine. Second, there must not be any disadvantages, compared to the fuel "ordinarily" used (hazardous emissions, power losses, odor, major fuel penalties, etc.). The mixture of acetal and EC 1 fuel almost fulfills the specification for Swedish environmental class 1 fuel and only minor differences can be noticed between the acetal/ diesel mixture and neat diesel (see Table 1). Larger differences are only observed for the distillation and flashpoint properties, which show lower values than specified. These lower values are probably results from the addition of acetal with flashpoint $\left(-20^{\circ} \mathrm{C}\right)$ and boiling point $\left(103.2^{\circ} \mathrm{C}\right)(18,24)$. Nevertheless, the analyzed properties of the mixture of diesel and acetal shows acceptable values to be regarded as a suitable diesel fuel.

Test Equipment and Test Conditions. All tests have been performed with the engine mounted on an engine test bed and connected to a Schenk/LE630 dynamometer controlled by a Schenk and AVL/PUMA system. The AVL/PUMA system was used to program the test conditions that were applied: the 13 modes of the European Stationary Cycle (ESC). Obtained engine/emission data were evaluated in accordance with the ESC test regulation (25).

A heated flame ionization detector (HFID) (model VE5, from J.U.M.) has been used to measure the total hydrocarbon (HC) content. Carbon monoxide (CO) and carbon dioxide $\left(\mathrm{CO}_{2}\right)$ were measured with two nondispersive infrared instruments Maihak UNOR $6 \mathrm{~N}$. NO and the thermally converted $\mathrm{NO}_{2}$ were determined using a chemiluminescence instrument (TECAN CLD700 ELHT) to yield the emissions of the various nitrogen oxides and the summarized value of $\mathrm{NO}_{x}$. Sampling was performed by pumping undiluted exhaust gas in heated sampling lines through the instrumentation. All instruments for measurements of regulated emissions and $\mathrm{CO}_{2}$ were purchased from BOO Instrument $\mathrm{AB}$, Saltsjö Boo, Sweden, together with a personal computer and software for control and collection of measurement data. Measure- ments of $\mathrm{NO}_{x}, \mathrm{HC}$, and $\mathrm{CO}$ content were performed in accordance with the ESC test cycles and were repeated nine times when the engine was operating on EC-1 diesel and five times when the engine was operating on A-diesel.

The software from BOO Instrument was also used for control and collection of measurement data obtained from sensors that were measuring pressure, temperature, and flow. Fuel consumption was determined by weight measurement, using a system constructed at Luleå University of Technology (LTU) in Sweden. The fuel weighing system also includes a means of heating the fuel using a heat exchanger.

Particles. Particles were sampled from the tailpipe with a commercial available mini-dilution system of the ejector pump-diluter type from Dekati Oy (Helsinki, Finland). The exhaust gas was diluted $\sim 44$ times with filtered and tempered compressed air at ambient temperature $\left(\sim 20^{\circ} \mathrm{C}\right)$. An SMPS (model 3936L25, from TSI, Inc., Shoreview, MN) has been used to measure the particle size and distribution. Particle sizes in the range of 9.65-422 $\mathrm{nm}$ were measured. Solid particles were measured two times (model 3065 Thermodenuder, from TSI, Inc., Shoreview, MN), and the total mass of particles were measured two times without the Thermodenuder. The measurements of solid and wet particles were made consecutively with and without the Thermodenuder. No corrections for particle loss in the Thermodenuder were made. Particle mass was calculated by the Aerosol Instrument Manager software that was supplied with the SMPS instrument.

Aldehydes. Formaldehyde, acetaldehyde, acrolein, and benzaldehyde were sampled by forcing undiluted exhaust gas samples through 2,4-dinitrophenylhydrazine (DNPH)coated cartridges (26). The connection between the tail pipe and the cartridges was heated to avoid condensation. Using high-pressure liquid chromatography (HPLC) and ultraviolet/ visible light (UV/VIS) detection, the aldehydes were later analyzed and identified to be 2,4-dinitrophenylhydrazones. The cartridges used were Sep-Pak DNPH silica (purchased from Waters).

Hydrocarbons. Analyses of hydrocarbons, ethane, ethene, acetylene, propane, propene, propyne, propadiene, isobutane, 1-butene, isobutene, toluene, and benzene were performed by directing exhaust gas sampled in Tedlar bags (made by SKC, Inc., Houston, TX) into a volatile organic compound (VOC) - air analyzer, a advanced gas chromatographic system, purchased from Chrompack (The Netherlands), which currently is part of Varian, Inc. (Palo Alto, CA). The hydrocarbons were sampled from the bag and concentrated cryogenically before injection onto the chromatographic column. The separated HCs were detected by the same technique as used for the other HC material (i.e., by HFID). Further information about the VOC-air analyzer and the method used can be found in ref 27 . Sampling was made in accordance to the procedure described by Lipari (28).

To minimize sample losses from stored Tedlar bags, all bags were stored in darkness and the time before analysis was kept as short as possible. These measures were taken to minimize the risk for reaction between the exhaust gas components and minimize the risk of sample loss $(28,29)$.

Acetal. Sampling of acetal was performed by bubbling exhaust gas in hexane, which was used as an impinger fluid. The impingers were kept cold using an ice bath. Acetal was later analyzed in a temperature-programmed gas chromatography (GC) system (Varian 3400, Varian, Inc., Palo Alto, CA) that was equipped with a J\&W Scientific capillary DB-1 column $(60 \mathrm{~m}$ in length and $0.32 \mathrm{~mm}$ in diameter, with a film thickness of $1.0 \mu \mathrm{m})$

\section{Results and Conclusion}

Particle size and distribution have been measured both as total particle size and distribution and as dry particle size 


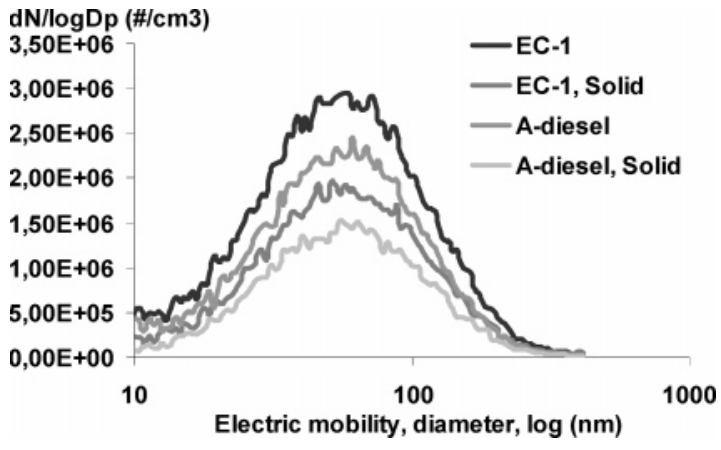

FIGURE 1. Weighted calculated particle size distributions, total and solid, for the engine operating in accordance with the European Stationary Cycle (ESC) test regulation.

TABLE 2. Particle Emissions with and without Wet Particles. Estimated Weighted Mass and Weighted Number Emissions in Accordance to ESC

\begin{tabular}{|c|c|c|c|}
\hline & $\begin{array}{c}\text { EC-1, } \\
\text { solid number }\end{array}$ & $\begin{array}{c}\text { EC-1, } \\
\text { total number }\end{array}$ & $\begin{array}{c}\text { solid/total } \\
(\%)\end{array}$ \\
\hline \multirow[t]{2}{*}{$\begin{array}{l}\text { EC-1 } \\
\text { A-diesel } \\
\text { decrease }\end{array}$} & $\begin{array}{l}1.14 \times 10^{16} \\
8.92 \times 10^{15} \\
\mathbf{2 1 . 8 \%}\end{array}$ & $\begin{array}{l}1.82 \times 10^{16} \\
1.40 \times 10^{16} \\
23.1 \%\end{array}$ & $\begin{array}{l}62.6 \\
63.7\end{array}$ \\
\hline & $\begin{array}{l}\text { EC-1, solid } \\
\text { (mg/kWh) }\end{array}$ & $\begin{array}{l}\text { EC-1, total } \\
\text { (mg/kWh) }\end{array}$ & $\begin{array}{c}\text { solid/total } \\
(\%)\end{array}$ \\
\hline $\begin{array}{l}\text { EC-1 } \\
\text { A-diesel } \\
\text { decrease }\end{array}$ & $\begin{array}{c}8.38 \\
5.53 \\
\mathbf{3 4 . 0 \%}\end{array}$ & $\begin{array}{c}11.8 \\
7.73 \\
34.6 \%\end{array}$ & $\begin{array}{l}71.0 \\
71.5\end{array}$ \\
\hline
\end{tabular}

and distribution. Wet particles, which are the volatile particles, are the share of the particles that originate from the combustion, unburned fuel, partly combusted fuel, oil fumes, water, and so forth (30). These exhaust gas constituents is most likely formed during low load and low speed conditions $(30,31)$. The low temperatures during these steps probably result in the inability of the chemical constituents to evaporate or react completely and, therefore, the constituents will condensate on the particles instead. As a consequence, the content of potentially cancer-causing pollutants, such as polyaromatic hydrocarbons (PAHs), has been determined to be higher in particulate formed at low temperatures than at higher temperatures (30).

The solid particles, i.e., the particles in the combustion aerosol that do not evaporate when they are exposed to higher temperatures, are particles that mainly consist of carbon $(30,32)$. The main part of all particles is carbonaceous and is formed under the combustion of the fuel in regions of the cylinder where the oxygen supply is insufficient (32).

The particle size distribution plot for the EC-1 fuel with and without addition of acetal is shown in Figure 1. As expected, the emitted particle number emissions were largest when the engine was operating on neat EC-1 fuel (see EC-1 plot in Figure 1 and number in Table 2). The emitted total particle number emissions was reduced by $23.1 \%$ when the engine was operating on A-diesel instead of EC-1 diesel (see Table 2).

Measurements with the Thermodenuder coupled before the SMPS instrument showed that only $62.6 \%$ of the particle number were solid (see EC-1 in Table 2). This means that $62.6 \%$ of the particles are soot and the remaining particles $(37.1 \%)$ are so-called wet particles when the engine is operating on neat diesel. The share of solid particles was determined to be approximately the same $(63.7 \%)$ when A-diesel was used. This indicates that the ratio between wet and solid particles is approximately the same for EC-1 and A-diesel.

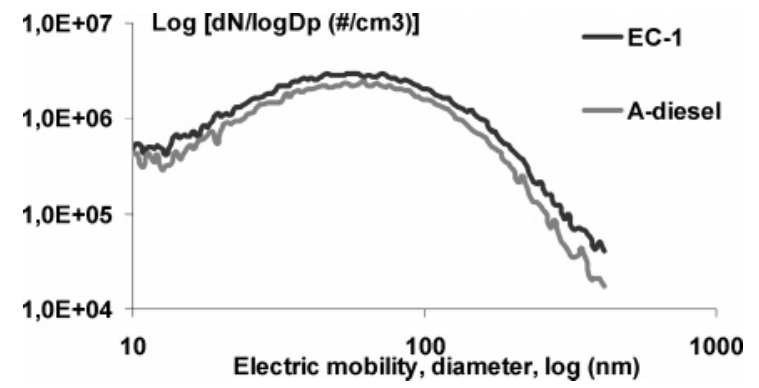

FIGURE 2. Weighted calculated logarithmic total particle size distributions for the engine operating in accordance to ESC.

To facilitate the interpretation of particle data, two figures were constructed that showed emitted particles when using EC-1 diesel or A-diesel. In the first figure (Figure 1), the weighted particle size distribution is shown. In the second figure (Figure 2), the logarithmic weighted particle size distribution is shown. It can easily be seen that the addition of acetal influences the particle size throughout all measured particle sizes; however, the influence seems to be somewhat higher on larger particle sizes, i.e., particles with a mobility diameter of $>130 \mathrm{~nm}$. This effect on particle size when using oxygenated fuels has also been observed by other researchers (16).

A plot of dry and wet particles for A-diesel and EC-1 (not shown here) revealed no major differences between the two fuels. Actually, the similarities were predominant; particulate emission was preferably formed during low load conditions with small differences between the wet/solid ratio that are formed during each operating condition. A trend that could be noticed was also that the content of wet particles was high at low loads and low speeds. The observed trend agrees with known facts, that volatile particles are formed in a higher degree during low-temperature conditions. In summary, acetal seems to influence particle emissions by reducing the number of particles during all operating conditions in all sizes with a somewhat higher reduction for the larger particles (i.e., larger than $130 \mathrm{~nm}$, as seen in Figure 2).

Particle mass was calculated from particle size and particle number data by the software provided. Particles $>422 \mathrm{~nm}$ in size were excluded, although, under real conditions, they have a substantial weight. The particle mass was calculated by assuming that the particle is a round sphere with a density of $1.2 \mathrm{~g} / \mathrm{cm}^{3}$, which is a value that has been retrieved from literature data (33). It must be stressed that calculation of the particle mass, using SMPS measurements and the software provided, is not coherent with the accreditation procedure, which uses weighing. This part of the investigation mostly detects changes and variations in particle mass.

A closer look at the estimated particle mass (see Table 2) supports the earlier finding that larger particles disappeared to a greater extent than smaller particles when adding acetal to diesel. The indication for this is that the reduction of particle mass was $34.6 \%$, whereas the reduction in particle number emissions was only $23 \%$ for the same event.

Measurements of $\mathrm{NO}_{x}, \mathrm{HC}$, and $\mathrm{CO}$ content were performed in accordance with the ESC test cycles (see Table 3). Notice that there is a small decrease in emitted $\mathrm{NO}_{x}$ emissions $(\sim 3.2 \%)$ when the engine is operating with A-diesel instead of neat EC-1 diesel. To confirm that the difference was statistically significant, a Student's $t$-test was performed (34). The test confirmed that the difference between the measured set of emission values for neat EC-1 diesel and A-diesel was significant at a $95 \%$ confidence interval. Thus, the $3.2 \%$ decrease in emitted $\mathrm{NO}_{x}$ emissions was statistically significant.

The increases in HC emission and CO emission $(4.9 \%$ and $3.8 \%$, respectively) were also statistically significant. An 
TABLE 3. Emissions of $\mathrm{NO}_{x}, \mathrm{CO}$, and Hydrocarbons (HCs), When Using EC-1 or A-Diesel

\begin{tabular}{llclcc} 
& \multicolumn{2}{c}{ Emission $(\mathbf{g} / \mathbf{k W h})$} & & \multicolumn{2}{c}{ Standard Deviation } \\
\cline { 2 - 3 } & EC-1 & A-diesel & & EC-1 & A-diesel \\
$\mathrm{NO}_{x}{ }^{a}$ & 6.78 & 6.56 & & 0.1125 & 0.0442 \\
$\mathrm{CO}$ & 0.5 & 0.48 & & 0.0124 & 0.0124 \\
$\mathrm{HC}$ & 0.58 & 0.55 & & 0.0077 & 0.0093
\end{tabular}

a The emissions of $\mathrm{NO}_{x}$ from the DC 902 engine were surprisingly high. A thorough investigation did not reveal the reason for this phenomenon.

explanation for these figures can be the lower cetane number of A-diesel, which may retard the start of combustion and, thus, result in the higher emissions of $\mathrm{HC}$ and $\mathrm{CO}$ that were observed (35). The lower cetane number may also explain the diminished $\mathrm{NO}_{x}$ formation that was observed (see Table 3) (32).

It is well-known that diesel exhaust gas is a complex mixture of hundreds of constituents in gas or particle form, many of which are environmental and health hazards (36). Exposure to benzene is known to increase the risk of leukemia (37). Alkenes such as ethene and propene are converted by metabolism in the human body to their corresponding epoxides, which may react in the cells and thus initiate a mutagenic effect (38). Formaldehyde and acetaldehyde are classified as probable carcinogens by the National Institute for Occupational Safety and Health (NIOSH), the World Health Organization (WHO), and the EU. A third aldehyde (acrolein) is listed as a possible human carcinogen by the U.S. Environmental Protection Agency (EPA) (37). Furthermore, the aldehydes, as a group, after nitrogen oxides, are one of the most powerful agents for smog formation in reaction with HCs (39).

All HCs, except for methane, participate in the formation of ground-level ozone (39). The potential to form ozone can be estimated by the maximum incremental reactivity (MIR) (40-42). A small difference in molecular structure can influence these factors substantially. For example, ethane has an MIR value of $0.35 \mathrm{mg} \mathrm{O}_{3} / \mathrm{mg}$ VOC, whereas ethene, which only differs from ethane by having two fewer hydrogens, has an MIR value of $9.97 \mathrm{mg} \mathrm{O}_{3} / \mathrm{mg}$ VOC and, thus, is a larger environmental threat. This further emphasizes the importance to evaluate compounds individually.

All of the already mentioned compounds have been selected for further investigation, together with some additional compounds. In total, 4 aldehydes were measured (formaldehyde, acetaldehyde, acrolein, and benzaldehyde), together with 12 hydrocarbons (ethane, ethene, acetylene, propane, propene, propyne, propadiene, isobutane, 1-butene, isobutene, benzene, and toluene).

To facilitate a comparison between the emissions obtained with and without the addition of acetal, weighted emissions factors were calculated, in accordance to the ESC test regulation (i.e., by multiplying emissions found in each of the steps in the ESC by the weighting factors used in the ESC). Thereby, one weighted value was obtained for each of the investigated compounds, representing the entire ESC (see Figures 3 and 4.

It soon became evident during the analysis that benzaldehyde was not detected in a majority of the steps in the ESC. Therefore, benzaldehyde was omitted from the following discussion.

Generally, an increase in emitted aldehyde emissions was observed when the engine was operating on A-diesel instead of neat EC-1 diesel. The formaldehyde, acetaldehyde, and acroleine contents increased, by $26 \%, 289 \%$, and $4.7 \%$, respectively. The moderate increase of formaldehyde and acroleine, compared to acetaldehyde, is probably due to the

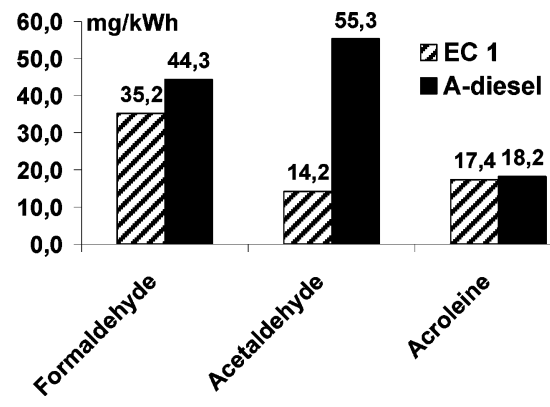

FIGURE 3. Aldehyde emissions with A-diesel and net EC-1 diesel.

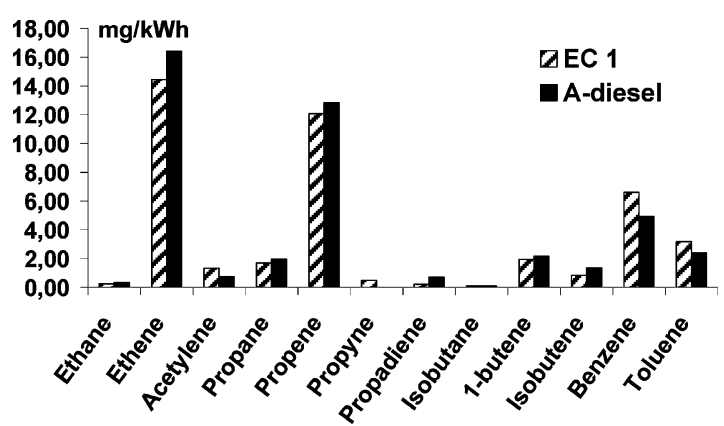

FIGURE 4. Hydrocarbon emissions with A-diesel and net EC-1 diesel.<smiles>CCOC(C)OCC</smiles>

FIGURE 5. Structure of 1,1-diethoxyethane (acetal).

somewhat more incomplete combustion, when the engine is operating on A-diesel instead of neat EC-1 diesel. The increase in acetaldehyde emission is most likely connected to the decomposition of acetal from the fuel in some way. An indication of this conclusion is that acetaldehyde and ethanol are used in the production of acetal (43). Second, the molecule (see Figure 5) can form advantageous, lowenergy, transition states, and if an elimination reaction or, alternatively, a radical reaction occurs with a following bond breakage, this yield acetaldehyde after rearrangement/ oxidation (44). In either case, if the acetal molecules easily decompose, the possibility of finding acetal in the exhaust gas would be low. Therefore, some additional tests were performed by sampling gas through ice-cooled impinger bottles filled with hexane and analyzing the samples thereafter using GC-FID. The limit of detection was $\sim 0.5 \mathrm{ppm}$ and acetal was only detected in 1 out of 13 modes (idle mode), supporting the view that acetal is easily decomposed. However, the subject should be further studied to establish the suggested conclusion.

Ethene, propene, benzene, and toluene belonged to the group of individual hydrocarbons that were most abundant in the exhaust gas. Unfortunately, these also were the most hazardous hydrocarbons of those investigated. The trend was that the polyunsaturated hydrocarbons (i.e., aromatic and alkynes) decreased whereas the unsaturated alkenes increased when using A-diesel. The investigated alkenesethane, propene, 1-butene, and isobutene-increased by $13.7 \%, 6.4 \%, 10.7 \%$, and $58.5 \%$, respectively, when the engine was operating on A-diesel instead of neat EC-1 diesel. The $58.5 \%$ increase in isobutene was from low levels; hence, the increase in real numbers was $0.5 \mathrm{mg} / \mathrm{kWh}$. The figures for the reduction of polyunsaturated compounds-acetylene, benzene, and toluene-were $44.3 \%, 25.3 \%$, and $24.4 \%$, when the engine was operating on A-diesel instead of EC-1 diesel. Propyne was detected only occasionally, and in low levels at that, when the engine was operating on A-diesel. The only 


\begin{tabular}{|c|c|c|c|}
\hline compound & $\begin{array}{c}\text { EC-1 } \\
(\mathrm{mg} / \mathrm{kWh})\end{array}$ & $\begin{array}{l}\text { A-diesel } \\
\text { (mg/kWh) }\end{array}$ & $\begin{array}{c}\text { MIR value } \\
\left.\text { (mg } 0_{3} / \mathrm{mg} \mathrm{VOC}\right)\end{array}$ \\
\hline formaldehyde & 35.2 & 44.3 & 9.12 \\
\hline acetaldehyde & 14.2 & 55.3 & 7.57 \\
\hline acroleine & 17.4 & 18.2 & 8.09 \\
\hline ethane & 0.24 & 0.32 & 0.35 \\
\hline ethene & 14.44 & 16.42 & 9.97 \\
\hline acetylene & 1.32 & 0.73 & 1.23 \\
\hline propane & 1.70 & 1.97 & 0.64 \\
\hline propene & 12.06 & 12.83 & 12.44 \\
\hline propyne & 0.49 & $\sim 0$ & 6.70 \\
\hline propadiene & 0.22 & 0.69 & 10.89 \\
\hline isobutane & 0.07 & 0.08 & 1.56 \\
\hline 1-butene & 1.94 & 2.15 & 10.80 \\
\hline isobutene & 0.85 & 1.34 & 6.81 \\
\hline benzene & 6.61 & 4.93 & 1.0 \\
\hline toluene & 3.16 & 2.39 & 4.19 \\
\hline
\end{tabular}

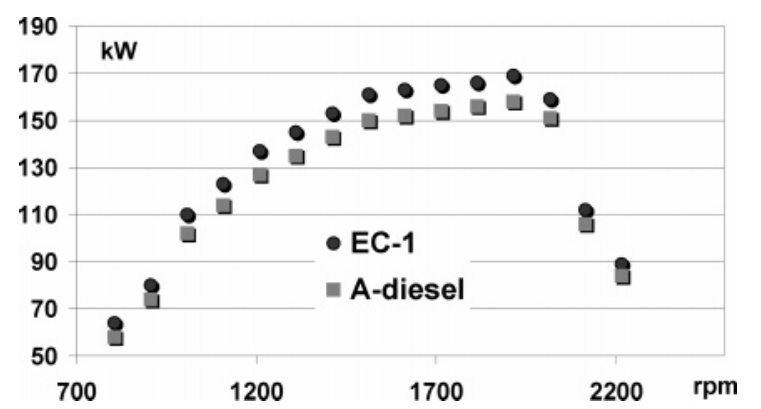

FIGURE 6. Power maps obtained when the engine is operating on neat EC-1 diesel and A-diesel.

exception from the observation that polyunsaturated compounds decreased when using A-diesel, was propadiene, which increased by $>200 \%$. However, the increase was from small figures (see Table 4).

The observation that compounds such as acetylene, propyne, benzene, and toluene decreased when acetal was added to diesel was interesting and consistent with the idea that these compounds have a role in the early stages of soot formation (32). The finding may indicate a possible association between the decrease in particle number emissions observed, when using A-diesel instead of neat EC-1 diesel, and the lower levels of presumed soot precursors.

A class of hydrocarbons that has not yet been mentioned is saturated hydrocarbons. The observed effect, when exchanging EC-1 diesel for A-diesel, was a small increase. Ethane emission increased from $0.24 \mathrm{mg} / \mathrm{kWh}$ to 0.32 $\mathrm{mg} / \mathrm{kWh}$, the propane level increased from $1.70 \mathrm{mg} / \mathrm{kWh}$ to $1.97 \mathrm{mg} / \mathrm{kWh}$, and the isobutane levels increased from 0.07 $\mathrm{mg} / \mathrm{kWh}$ to $0.08 \mathrm{mg} / \mathrm{kWh}$.

To summarize the effect of aldehydes and hydrocarbons on the environment, the accumulated MIR effect was calculated from the values given in Table 4 . The conclusion is that the ground-level ozone content will increase by $46 \%$ when A-diesel is used instead of EC-1 diesel. However, if acetaldehyde is excluded from the calculations, the change is only $13.1 \%$. Thus, of these investigated compounds, acetaldehyde is the compound responsible for the major portion of the change.

Engine performance was also compared when using the two different fuels (see Figure 6). The power output was higher when the engine was operating on EC-1 diesel instead of A-diesel. This was what could be expected because A-diesel has lower energy content than EC-1 diesel (see Table 1). Yet, this cannot explain the entire difference obtained, when comparing the average power loss $(6.7 \%)$ with the $3 \%$ lower heat value.

The largest losses of power (expressed as a percentage) were observed at low speeds. Between 800 and $1700 \mathrm{rpm}$, the power losses were between $7.5 \%$ and $6.5 \%$, whereas higher speeds (i.e., $>2000 \mathrm{rpm}$ ), the power losses are $\sim 5.5 \%$. Nevertheless, there is a gap between the energy content and the power losses, even though the gap decreases when the speed increases. A possible explanation for the observed trend between the expected and observed power losses is that the oxygen in the fuel is not fully utilized at low speed. When the speed increases, the oxygen in the fuel is utilized more. The remaining difference may be attributed to engine-specific influences, from the engine design, which strongly affect fuel consumption and efficiency (32). However, efficiency may be compensated for with engine tuning that better suits the A-diesel.

A consequence of the lower energy content of A-diesel was also $4 \%$ higher specific fuel consumption. Specific fuel consumption was $223.6 \mathrm{~g} / \mathrm{kWh}$ for A-diesel and $215.0 \mathrm{~g} / \mathrm{kWh}$ for EC-1 diesel when operating according to the steps in the ESC. However, if one consider the fact that $10 \%$ of A-diesel consisted of acetal that originated from biomass, the net contribution of $\mathrm{CO}_{2}$ to the atmosphere actually diminished by $\sim 6.4 \%$, despite the higher fuel consumption that was observed.

\section{Summary}

The investigation has shown that acetal is suitable as a blending component to diesel fuel. Acetal can be made from bio-based ethanol, and when it is blended into diesel, the fuel mixture develops qualities similar to the diesel fuel into which it is blended. Furthermore, A-diesel has beneficial effects on some of the emission components. Particle number emission decreased by $23 \%$, estimated particulate mass emissions decreased by $34.6 \%$, and $\mathrm{NO}_{x}$ emissions decreased by $3.2 \%$. Unfortunately, CO and HC emission increased by $3.8 \%$ and $4.9 \%$, respectively. Minor changes were observed in the levels of the investigated aldehydes and hydrocarbons, when operating the engine with and without the addition of acetal. One exception to this was the acetaldehyde emissions, which increased as much as $289 \%$ when using A-diesel. There was a small power loss and a small fuel penalty was noticed when the engine was operating on A-diesel. Nevertheless, a reduction of $6.4 \%$ of the net contribution of $\mathrm{CO}_{2}$ emissions to the atmosphere was achieved, when considering that the acetal was made from biomass. Because of the fact that the emissions of particles, $\mathrm{NO}_{x}$, and $\mathrm{CO}_{2}$ decreased when the engine was operating on the acetal mixture compared to EC-1 fuel, a cautious conclusion is that A-diesel can be more beneficial as an automotive fuel than EC-1 diesel. However, one must recall that the result is from a single engine, there were higher levels of acetaldehyde, and many components in the exhaust gas remain unanalyzed. However, the increase in engine-out emissions of acetaldehyde can probably be reduced by exhaust gas after treatment (e.g., a catalyst), which most likely will be a necessity to achieve future regulation specifications.

\section{Acknowledgments}

The authors fully acknowledge SEKAB, The Swedish Ethanol Chemistry Company, who financed this investigation. Grants from Kempestiftelserna, Örnsköldsvik, are gratefully acknowledged.

\section{Literature Cited}

(1) On the Promotion of Use of Biofuels or other Renewable Fuels for Transport, Eu-directive EU 2003 Directive 2003/30/EC from the European Parliament and the Council, May 8, 2003. 
(2) Hansen, A. C.; Zhang, Q.; Lyne, P. W. L. Ethanol-diesel fuel blends-a review. Bioresource Technol. 2005, 96, 277-285.

(3) Corkwell, K. C.; Jackson, M. M.; Daly, D. T. Review of Exhaust Emissions of Compression Ignition Engines Operating on E Diesel Fuel Blends. SAE Tech. Pap. Ser. 2003, 2003-01-3283.

(4) Hood, J.; Farina, R. Emissions from Light Duty Vehicles Operating on Oxygenated Fuels at Low Ambient Temperatures: A Review of Published studies. SAE Tech. Pap. Ser. 1995, 952403.

(5) He, B.-Q.; Wang, J.-X.; Yan, X.-G.; Tian, X.; Chen, H. Study on Combustion and Emission characteristics of Diesel Engines Using Ethanol Blended Diesel Fuels. SAE Tech. Pap. Ser. 2003, 2003-01-0762.

(6) Stoner, M.; Litzinger, T. Effects of Structure and Boling Point of Oxygenated Blending Componds in Reducing Diesel Emissions. SAE Tech. Pap. Ser. 1999, 1999-01-1475.

(7) Bertola, A.; Boulouchos, K. Oxygenated Fuels for Particulate Emissions Reduction in Heavy-Duty DI-Diesel Engines with Common-Rail Fuel Injection. SAE Tech. Pap. Ser. 2000, 200001-2885.

(8) Mohanan, P.; Kapilan, N.; Reddy, R. P. Effect of Diethyl ether on the Performance and Emission of a 4-S DI Diesel Engine. SAE Tech. Pap. Ser. 2003, 2003-01-0760.

(9) He, B.-Q.; Wang, J.-X.; Yan, X.-G.; Tian, X.; Chen, H. Study on Combustion and Emission characteristics of Diesel Engines Using Ethanol Blended Diesel Fuels. SAE Tech. Pap. Ser. 2003, 2003-01-0762.

(10) Kass, M. D.; Thomas, J. F.; Storey, J. M.; Domingo, N.; Wade, J.; Kenreck, G. Emissions from a 5.9 Liter Diesel Engine Fueled with Ethanol Diesel Blends. SAE Tech. Pap. Ser. 2000, 200001-2018.

(11) Ball, J. C.; Gonzales, M. A.; Lapin, C.; Liney, E.; Buckingham, J.; Frame, E.; Yost, D.; Natarajan, M.; Garbak, J.; Wallace, J. P., III. Dimethoxy Methane in Diesel Fuel: Part 1. The Effect of Fuels and Engine Operating Modes on Emissions of Toxic Air Pollutants and Gas/Solid-Phase PAH. SAE Tech. Pap. Ser. 2001, 2001-01-3627.

(12) Ball, J. C.; Gonzales, M. A.; Lapin, C.; Liney, E.; Buckingham, J.; Frame, E.; Yost, D.; Natarajan, M.; Garbak, J.; Wallace, J. P., III. Dimethoxy Methane in Diesel Fuel: Part 2. The Effect of Fuels on Emissions of Toxic Air Pollutants and Gas/Solid-Phase PAH Using a Composite of Engine Operation Modes. SAE Tech. Pap. Ser. 2001, 2001-01-3628.

(13) Ball, J. C.; Gonzales, M. A.; Lapin, C.; Liney, E.; Buckingham, J.; Frame, E.; Yost, D.; Natarajan, M.; Garbak, J.; Wallace, J. P., III. Dimethoxy Methane in Diesel Fuel: Part 3. The Effect of Pilot Injection, Fuels and Engine Operating Modes on Emissions of Toxic Air Pollutants and Gas/Solid-Phase PAH. SAE Tech. Pap. Ser. 2001, 2001-01-3630.

(14) Cheng, A. S.; Dibble, R. W.; Buchholz, B. A. The effect of Oxygenates on Diesel Engine Particulate Matter. SAE Tech. Pap. Ser. 2002, 2002-01-1705.

(15) Hilden, D. L.; Eckstrom J. C.; Wolf, L. R. The emissions of Oxygenated Diesel Fuels in a Prototype DI Diesel Engine. SAE Tech. Pap. Ser. 2001, 2001-01-0650.

(16) Hallgren, B. E.; Heywood, J. B. Effects of Oxygenated Fuels on DI Diesel Combustion and Emissions. SAE Tech. Pap. Ser. 2002, 2002-01-0648.

(17) Yeh, L. I.; Rickeard, J. L.; Duff, J. L. C.; Bateman, J. R.; Schlosberg, R. H.; Caers, R. F. Oxygenates: An Evaluation of their Effects on Diesel Emissions. SAE Tech. Pap. Ser. 2001, 2001-01-2019.

(18) Natarajan, M.; Gonzalez, M. A.; Frame, E. A.; Naegeli, D. W.; Liney, E.; Asmus, T.; Piel, P.; Clark, W.; Wallace, J. P.; Garbak, J. Oxygenates for Advanced Petroleum-Based Diesel Fuels: Part 1. Screening and Selection Methodology for the Oxygenates. SAE Tech. Pap. Ser. 2001, 2001-01-3631.

(19) Gonzales, M. A.; Liney, E.; Piel, W.; Natarajan, M.; Asmus, T.; Naegeli, D. W.; Yost, D.; Frame, E. A.; Clark, W.; Wallace, J. P.; Garbak, J. Oxygenates for Advanced Petroleum-Based Diesel Fuels: Part 2. The Effect of Oxygenate Blending Compounds on Exhaust Emissions. SAE Tech. Pap. Ser. 2001, 2001-01-3632.

(20) Bertola, A.; Schubiger, R.; Kaspar, A.; Matter, U.; Forss, A. M.; Mohr, M.; Boulouchos, K.; Lutz, T. Characterization of Diesel Particulate Emissions in Heavy-Duty DI-Diesel Engines with Common Rail fuel Injection Influence of Injection Parameters and fuel composition. SAE Tech. Pap. Ser. 2001, 2001-01-3573.

(21) Miaymoto, N.; Ogawa, H.; Arima; Miyakawa, K. Improvement of Diesel Combustion and Emissions with Addition of Various Oxygenated compounds. SAE Tech. Pap. Ser. 1996, 962115.

(22) Haupt, D.; Nord, K.; Tingvall, B.; Ahlvik, P.; Egebäck, K.-E.; Andersson, S. Blomquist, M. Investigating the potential to obtain low emissions from a diesel engine running on ethanol and equipped with EGR, catalyst and DPF. SAE Tech. Pap. Ser. 2004, 2004-01-1884.

(23) Chatterjee, S.; Conway, R.; Viswanathan, S.; Blomquist, M.; Klüsener, B.; Andersson, S. $\mathrm{NO}_{x}$ and PM control from Heavy Duty Diesel Engines using a combination of low pressure EGR and Continuously Regenerating Diesel Particulate Filter. $S A E$ Tech. Pap. Ser. 2003, 2003-01-0048.

(24) Handbook of Chemistry and Physics, 63rd Edition; CRC Press: Boca Raton, FL, 1982-1983. (ISBN No. 0-8493-0463-6.)

(25) On the approximation of the laws of the Member States relating to measures to be taken against the emission of gaseous and particulate pollutants from compression ignition engines for use in vehicles, and the emission of gaseous pollutants from positive ignition engines fuelled with natural gas or liquefied petroleum gas for use in vehicles and amending Council Directive 88/77/EEC, Eu-directive EU 1999 Directive 1999/96/ EC from the European Parliament and the Council, December 13, 1999 .

(26) Iraneta, P. Waters XPoSure ${ }^{T M}$ Aldehyde Sampling Cartridges for Air Monitoring Applications; Waters Sample Prep Notes; Waters Corporation: Milford, MA, 1995; Vol. SPN 4.

(27) Haupt, D.; Nord, K.; Ahlvik, P.; Egebäck, K.-E. Hydrocarbons and aldehydes from a diesel engine running on ethanol and equipped with EGR, catalyst and DPF. SAE Tech. Pap. Ser. 2004, 2004-01-1882.

(28) Lipari, F. Determination of individual hydrocarbons in automobile exhaust from gasoline-, methanol-, and variable-fueled vehicles. J. Chromatogr. 1990, 503, 51-68.

(29) Jensen, T. E.; Siegl, W. O.; Richert, J. F. O.; Lipari, F.; Loo, J. F.; Prostak, A.; Sigsby, J. E. Advanced Emission Speciation Methodologies for the Auto/Oil Air Quality Improvement Research Program-1. Hydrocarbons and Ethers. SAE Tech. Pap. Ser. 1992, 920320.

(30) Kittelson, D. B. Engines and nanoparticles: A review. J. Aerosol Sci. 1998, 29 (5/6), 575-588.

(31) Nord, K.; Haupt, D.; Ahlvik, P.; Egebäck, K. E. Particulate Emissions from an Ethanol Fueled Heavy-Duty Diesel Engine Equipped with EGR, Catalyst and DPF. SAE Tech. Pap. Ser. 2004, 2004-01-1987.

(32) Heywood, J. B. Internal Combustion Engine Fundamentals McGraw-Hill: New York, 1988. (ISBN-0-07-028637-x.)

(33) Virtanen, A.; Ristimäki, J.; Marjamäki, M.; Vaaraslahti, K.; Keskinen, J. Effective Density of Diesel Exhaust Particles as a function of Size. SAE Tech. Pap. Ser. 2002, 2002-01-0056.

(34) Harris, D. C. Quantitative Chemical Analysis, Sixth Edition; W. H. Freeman and Co.: New York, 2003. (ISBN 0-7167-4464-3.)

(35) Owen, K.; Coley, T.Automotive Fuels Reference Book, 2nd Edition; Society of Automotive Engineers: Warrendale, PA, 1995. (ISBN 1-56091-589-7.)

(36) Health Assessment Document for Diesel Engine Exhaust, No. EPA/600/8-90/057F, U.S. Environmental Protection Agency, Washington, DC, 2002.

(37) Cancer risk from outdoor air toxics, Vol. 1; U.S. Environmental Protection Agency, Washington, DC, 1990; pp 450-451.

(38) Törnqvist, M.; Ehrenberg, L. On Cancer Risk Health Risk Perspectives; 1994; pp 173-182.

(39) Manahan, S. E. Environmental Chemistry, 7th Edition; Lewis Publishers: Boca Raton, FL, 2000. (ISBN 1-56670-492-8.)

(40) Nord, K.; Haupt, D. Evaluating a Fischer-Tropsch fuel, Eco$\mathrm{Par}^{\mathrm{TM}}$ in a Valmet Diesel Engine. SAE Tech. Pap. Ser. 2002, 2002 01-2726.

(41) Carter, W. Proposed reactivity adjustment factors for transitional low emission vehicles, State of California Air Resources Board Technical Support document, 1991.

(42) Carter, W. Updated Maximum Incremental Reactivity Scale for Regulatory Applications Preliminary Report to California Air Resources Board, Contract No. 95-308 (http://pah.cert.ucr.edu/ $\sim$ carter/r98tab.htm).

(43) Capletti, M. R.; Balzano, L.; de la Punte, G.; Laborde, M.; Sedran, U. Synthesis of acetal (1,1-diethoxyethane) from ethanol and acetaldehyde over acid catalysts. Appl. Catal., A 2000, 198, $\mathrm{Ll}-4 \mathrm{~L}$.

(44) Solomons, T. W.G. Organic Chemistry, Fourth Edition; Wiley: New York, 1988. (ISBN 0-471-62942-1.)

Received for review December 4, 2004. Accepted May 10, 2005.

\section{ES048085H}

